Check for updates

Cite this: RSC Adv., 2018, 8, 3964

Received 26th December 2017 Accepted 15th January 2018

DOI: $10.1039 / c 7 r a 13650 a$

rsc.li/rsc-advances

\section{Green controllable synthesis of Au-Ag alloy nanoparticles using Chinese wolfberry fruit extract and their tunable photocatalytic activity $\dagger$}

\begin{abstract}
Li Sun, (D) * Yuechao Yin, Pengcheng Lv, Wenxian Su and Lixin Zhang
The controllable synthesis of Au-Ag alloy nanoparticles (NPs) without any hazardous or expensive chemical agent has been a challenge. This paper reports on the Chinese wolfberry fruit extract-assisted synthesis of $\mathrm{Au}-\mathrm{Ag}$ alloy NPs with homogeneous composition, uniform alloy microstructure and a small average size less than $15 \mathrm{~nm}$. The composition and the surface plasmon resonance (SPR) wavelength of Au-Ag alloy NPs could be linearly adjusted by the synthesis time in one-pot. Au-Ag alloy NPs were characterized by means of various techniques, and then their synthesis mechanism was discussed. The obtained Au-Ag alloy NPs were used as photocatalysts for the reduction reactions of 2-, 3-, and 4-nitrophenol and exhibited superior photocatalytic activity and stability. The rate constants of the above photocatalytic reactions could be linearly tuned by the composition of the Au-Ag alloy NPs and also by their addition amount, displaying a new method to control the rate constant. Furthermore, based on the controllable synthesis, the rate constant could even be predetermined just through setting the synthesis parameters of the Au-Ag alloy NPs.
\end{abstract}

\section{Introduction}

$\mathrm{Au}-\mathrm{Ag}$ alloy NPs have attracted increasing attention due to their interesting catalytic, electronic, and optical properties..$^{1-6} \mathrm{Up}$ to now, $\mathrm{Au}-\mathrm{Ag}$ alloy NPs have been prepared through different physical and chemical methods, including spray pyrolysis, phase-transfer, digestive ripening, co-reduction of $\mathrm{Au}$ and $\mathrm{Ag}$ salts, and galvanic replacement reactions..$^{7-11}$ Among these methods, chemical methods are most widely used for the synthesis of homogeneous Au-Ag alloy NPs. However, chemical methods can't avoid the addition of toxic chemicals and strong ligands in their synthesis protocols, which can pose potential environmental and biological risks. ${ }^{12,13}$ In recent years, green synthesis methods, employing microorganisms or plant extracts as reductants, have been considered as an eco-friendly alternative to physical and chemical methods because of their obvious advantages in safety, cost-effectiveness and biocompatibility. ${ }^{14-17}$ In particular, the green synthesis methods based on plant extracts provide a promising choice for the synthesis of $\mathrm{Au}-\mathrm{Ag}$ alloy NPs. Nevertheless, only a few kinds of plants, such as Cacumen platycladi leaf extract, Silybum marianum seed extract, and the fruit juice of pomegranate, were used to prepare $\mathrm{Au}-\mathrm{Ag}$ alloy NPs. ${ }^{18-20}$ In these green synthesis methods, the ratio of $\mathrm{Au}$ element and $\mathrm{Ag}$ element in the obtained $\mathrm{Au}-\mathrm{Ag}$ alloy NPs

School of Energy and Power Engineering, University of Shanghai for Science and Technology, Jun Gong Road 516, Shanghai 200093, China. E-mail: marybrother@ yeah.net; Fax: +8621 55272376; Tel: +862155272740

$\dagger$ Electronic supplementary information (ESI) available. See DOI: 10.1039/c7ra13650a is nearly equal to the $\mathrm{Au}^{3+} / \mathrm{Ag}^{+}$ratio in the raw materials. The above synthesis methods employ a point-to-point synthesis route, by which it is difficult to continuously adjust the composition of $\mathrm{Au}-\mathrm{Ag}$ alloy NPs in one-pot.

The main application of Au-Ag alloy NPs lies in the field of catalysis. Initially, $\mathrm{Au}-\mathrm{Ag}$ alloy NPs were applied into the lowtemperature $\mathrm{CO}$ oxidation reaction and revealed a strong synergistic effect between $\mathrm{Au}$ and $\mathrm{Ag}$ element. ${ }^{3}$ Recently, it was reported $\mathrm{Au}-\mathrm{Ag}$ alloy NPs exhibited obvious photocatalytic activities for the degradations of many organic compounds under abundant sunlight irradiation. ${ }^{21}$ Compared with semiconductor photocatalysts $\left(\mathrm{TiO}_{2}, \mathrm{WO}_{3}, \mathrm{ZnO}\right), \mathrm{Au}-\mathrm{Ag}$ alloy NPs can make full use of solar photons in the visible spectral region. ${ }^{2-24}$ Generally, the reduction of aromatic nitro compound as a model reaction is used to confirm the photocatalytic activity of noble metal NPs. ${ }^{20,25,26}$ The nitro $\left(-\mathrm{NO}_{2}\right)$ group in nitro phenols is relatively stable in biological systems and can cause health hazards in humans and animals. ${ }^{27}$ The single product of the reduction of nitrophenol (NP) is non-toxic aminophenol (AP), which is an important intermediate in the manufacture of many analgesic and antipyretic drugs. Clearly, it is necessary to converse NP to AP via photocatalysts with a high activity. The photocatalytic activity of Au-Ag alloy NPs is mainly dependent on their composition besides their addition amount. ${ }^{20}$ As of today, there has been no definite correlation between the photocatalytic activity of Au-Ag alloy NPs and their composition.

The Chinese wolfberry fruit, an ancient Chinese herbal medicine, has strong bactericidal action, low price and wide distribution in China. To the best of authors' knowledge, few 
works in literature reported a totally green and fast synthesis of $\mathrm{Au}-\mathrm{Ag}$ alloy NPs using the Chinese wolfberry fruit extract as reductant and surfactant without the addition of any chemical agent. ${ }^{28}$ In this paper, based on the Chinese wolfberry fruit extract, we tried to synthesize homogeneous $\mathrm{Au}-\mathrm{Ag}$ alloy NPs in one-pot. In order to realize the controllable synthesis of $\mathrm{Au}-\mathrm{Ag}$ alloy NPs, the synthesis parameters, including the $\mathrm{Au}^{3+} / \mathrm{Ag}^{+}$ molar ratio in raw materials and the synthesis time, were investigated systematically. Au-Ag alloy NPs were characterized by FT-IR, UV-vis, EDX, ICP, XPS, TEM, HR-TEM, and SAED, and then a possible synthesis mechanism was further deduced. Obtained $\mathrm{Au}-\mathrm{Ag}$ alloy NPs were used as photocatalysts for the reduction reactions of 2-, 3-, 4-NP and their photocatalytic properties were studied in details.

\section{Experimental section}

\section{Materials}

Silver nitrate $\left(\mathrm{AgNO}_{3}, \mathrm{GR}\right)$, chloroauric acid $\left(\mathrm{HAuCl}_{4} \cdot 3 \mathrm{H}_{2} \mathrm{O}, \mathrm{AR}\right)$, sodium borohydride $\left(\mathrm{NaBH}_{4}, \mathrm{AR}\right)$, 4-nitrophenol $\left(\mathrm{C}_{6} \mathrm{H}_{5} \mathrm{NO}_{3}\right.$, AR), 3-nitrophenol $\left(\mathrm{C}_{6} \mathrm{H}_{5} \mathrm{NO}_{3}, \mathrm{AR}\right)$, 2-nitrophenol $\left(\mathrm{C}_{6} \mathrm{H}_{5} \mathrm{NO}_{3}, \mathrm{AR}\right)$ and ethanol $\left(\mathrm{C}_{2} \mathrm{H}_{5} \mathrm{OH}, \mathrm{GR}\right)$ were purchased from Aladdin Reagent Inc. (Shanghai, China) and used directly as raw materials without further treatment. Deionized water was used throughout this work. In the experiment, the Chinese wolfberry fruit (Lycium barbarum L.) were produced in Ningxia province of China.

\section{Preparation of Chinese wolfberry fruit extract}

$3 \mathrm{~g}$ of wolfberry fruit and $250 \mathrm{~mL}$ of deionized water were mixed and brought to boiling for $8 \mathrm{~min}$ under vigorous stirring. The above boiling solution was cooled in air until to room temperature. Then the cooled solution was centrifuged at $8000 \mathrm{rpm}$ for $8 \mathrm{~min}$ to remove any undesired impurities. Obtained wolfberry fruit extracts were used for further experiments.

\section{Green synthesis of Au-Ag alloy NPs}

$\mathrm{Au}-\mathrm{Ag}$ alloy NPs were synthesized by the co-reduction of $\mathrm{HAuCl}_{4}$ and $\mathrm{AgNO}_{3}$ in one-pot. The $\mathrm{Au}^{3+} / \mathrm{Ag}^{+}$molar ratio in raw materials was individually set at $1: 5,1: 3.5$, and $1: 1$. The concentration of $\mathrm{HAuCl}_{4}$ and $\mathrm{AgNO}_{3}$ was $0.1 \mathrm{M}$ and $0.01 \mathrm{M}$, respectively. The amount of $\mathrm{HAuCl}_{4}$ aqueous solution was fixed at $10 \mu \mathrm{L}$ in the whole experiment. Typically, $10 \mathrm{~mL}$ of wolfberry fruit extract was taken in a round bottom flask and gently heated to boiling with stirring. After $10 \mathrm{~min}, 60 \mathrm{~mL}$ of the mixture consisted of $10 \mu \mathrm{L} \mathrm{HAuCl}_{4}$ solution and $500 \mu \mathrm{L} \mathrm{AgNO}$ solution was added into the above boiling aqueous solution. The synthesis system was kept boiling with continuous stirring till the end of the reaction. The synthesis time was set at 0.5, 2, 5, 10 and 15 min to obtain different $\mathrm{Au}-\mathrm{Ag}$ alloy NPs.

\section{Characterization}

The zeta potential (Zeta PLAS, Malvern Instruments) was used to analyze the potential stability of $\mathrm{Au}-\mathrm{Ag}$ alloy NPs synthesized by the Chinese wolfberry fruit extract. Ultraviolet visible spectrum (UV-vis) analysis was carried out on a spectrophotometer (Cary 50, Varian) using deionized water as the dispersing agent. The concentrations of Au element and Ag element were measured by means of Varian 710 inductively coupled plasma spectrometry (ICP-MS). The samples for ICP were solubilized in aqua regia $\left(\mathrm{HCl} / \mathrm{HNO}_{3}\right)$ in advance. X-ray photoelectron spectroscopy (XPS) was acquired by a spectrometer (ESCALAB 250Xi, Thermo Fisher Scientific). X-ray diffraction (XRD) patterns were recorded on the X-ray diffractometer (D/MAX $2550 \mathrm{VB} / \mathrm{PC}$, Rigaku). The samples for XPS and XRD were made by depositing NPs on silicon wafers. Transmission electron microscope (TEM), high resolution transmission electron microscope (HR-TEM), energydispersive X-ray spectroscopy (EDX) and selected area electron diffraction (SAED) analyses were performed on an electron microscope system (JEM-2100F, JEOL). The samples for above analyses were prepared by depositing a drop of NPs hydrosol on an amorphous carbon-copper grid and then drying at room temperature in air. For each sample, the average diameter and the standard deviation were determined by averaging measurements of more than 100 NPs. Fouriertransform infrared spectroscopy (FT-IR) was achieved on a spectrophotometer (FT/IR-4200, JASCO) in the wavenumber range $4000-400 \mathrm{~cm}^{-1}$ in air. The sample was obtained by mixing the specimen with $100 \mathrm{mg}$ of $\mathrm{KBr}$ powders and pressing the mixture into a sheer slice.

\section{Photocatalytic reduction of 2-, 3-, 4-nitrophenol}

The reduction reactions of nitrophenol (2-, 3-, 4-NP) under sunlight irradiation were performed to investigate the photocatalytic activity of Au-Ag alloy NPs. Typically, $2.5 \mathrm{~mL}$ of $1 \mathrm{M}$ freshly prepared aqueous solution of $\mathrm{NaBH}_{4}$ was mixed with $2.5 \mathrm{~mL}$ of $10 \mathrm{mM}$ nitrophenol in a standard quartz cuvette. Then $500 \mu \mathrm{L}$ of $0.1 \mathrm{mM} \mathrm{Au}-\mathrm{Ag}$ alloy NPs hydrosol was added into the above mixed solution as photocatalyst. After that, the UV-vis spectra were recorded at every $5 \mathrm{~min}$ interval in the range of $600-250 \mathrm{~nm}$ at $30 \pm 0.2{ }^{\circ} \mathrm{C}$. The reduction reactions of nitrophenol were followed by monitoring the changes in the absorbance of the initially observed peak at $400 \mathrm{~nm}$ for the nitrophenolate anions as a function of time. In order to research the effect of the addition amount of Au-Ag alloy NPs hydrosol on the rate constant, the addition amount was set at $0.5,1.0,1.5,2.0,2.5$, and $3.0 \mathrm{~mL}$, respectively. $\mathrm{Au}-\mathrm{Ag}$ alloy NPs were stored at $20^{\circ} \mathrm{C}$ and their photocatalytic activity was measured at every 15 days up to 3 months.

\section{Results and discussion}

\section{Analysis of the Chinese wolfberry fruit extract}

FT-IR spectroscopy is used to identify possible functional groups in the Chinese wolfberry fruit extract. These functional groups are responsible for the reduction of ions $\left(\mathrm{Au}^{3+}\right.$ and $\left.\mathrm{Ag}^{+}\right)$ and the stabilization of obtained $\mathrm{Au}-\mathrm{Ag}$ alloy NPs. It was reported that the wolfberry fruit contained carbohydrate (polysaccharide, glycosides), alcohols, proteins, amino acids, amines, amides, alkanes, lipids, and so on. ${ }^{29}$ As shown in Fig. 1a, the spectrum of the wolfberry fruit extract before the 


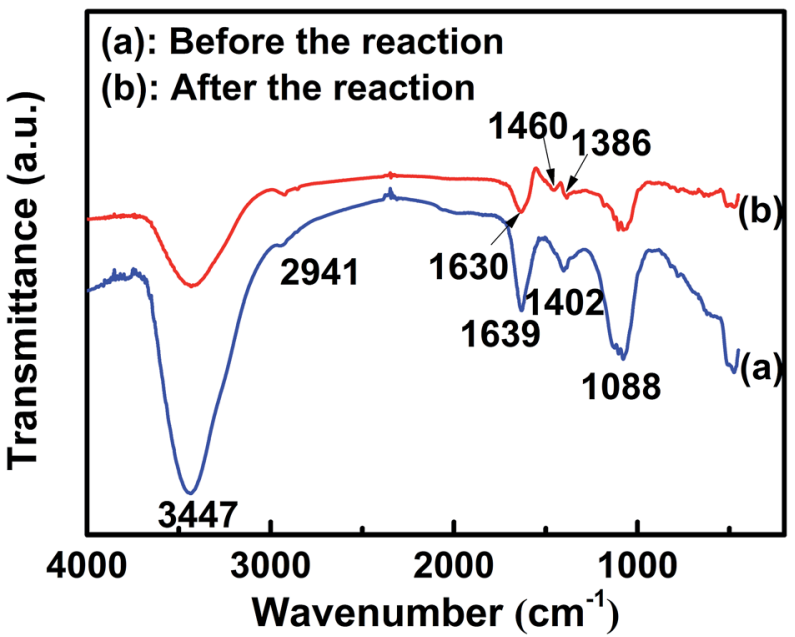

Fig. 1 FT-IR spectra of the wolfberry fruit extract before the reaction (a) and the wolfberry fruit extract with $\mathrm{Au}_{0.25} \mathrm{Ag}_{0.75}$ alloy NPs after the reaction (b).

reaction displays a number of vibration bands at 3447, 2941, 1639,1402 , and $1088 \mathrm{~cm}^{-1}$. The spectrum exhibits a broad band located at $3447 \mathrm{~cm}^{-1}$, which can be assigned to the $\mathrm{O}-\mathrm{H}$ stretching vibrations in hydroxyl groups (absorbed water or alcohols) and $\mathrm{N}-\mathrm{H}$ stretching vibrations in amino groups (amides, amines, amino acids, or proteins). The weak band at $2941 \mathrm{~cm}^{-1}$ can arise from the $\mathrm{C}-\mathrm{H}$ stretching vibrations in alkanes. The band at $1639 \mathrm{~cm}^{-1}$ can correspond to amide I band or the $\mathrm{O}-\mathrm{H}$ bending vibrations in carbohydrate. ${ }^{30}$ The band at $1402 \mathrm{~cm}^{-1}$ can be ascribed to the $-\mathrm{C}-\mathrm{N}$ stretching vibrations of amide III band. The band at $1088 \mathrm{~cm}^{-1}$ can be attributed to the $-\mathrm{C}-\mathrm{OH}$ vibrations derived from carbohydrate and alcohols. In Fig. $1 \mathrm{~b}$, the new band at $1460 \mathrm{~cm}^{-1}$ can originate from the methylene scissoring vibrations of proteins..$^{30}$ After the reaction (Fig. 1b), the decrease in intensity at 1639, 1402 and $1088 \mathrm{~cm}^{-1}$ is exhibited, which illustrates proteins, amides, carbohydrate and alcohols can be responsible for the reduction of $\mathrm{Au}$ ions and Ag ions. And the significant shifts of bands from $1639 \mathrm{~cm}^{-1}$ to $1630 \mathrm{~cm}^{-1}$ and from $1402 \mathrm{~cm}^{-1}$ to $1386 \mathrm{~cm}^{-1}$ are shown, which can be caused due to the binding of functional groups with $\mathrm{Au}-\mathrm{Ag}$ alloy NPs. ${ }^{18}$ These functional groups covered on the surface of $\mathrm{Au}-\mathrm{Ag}$ alloy NPs can involve proteins, amides, and carbohydrate, which act as surfactants to prevent the aggregation of NPs. ${ }^{31}$ Obviously, it is possible to synthesize $\mathrm{Au}-\mathrm{Ag}$ alloy NPs for those plants containing the proteins, amides, carbohydrate and alcohols.

Generally, the concentration of plant extracts has an influence on the stability of synthesized NPs. ${ }^{19}$ In our experiment, the concentration of wolfberry fruit extract is fixed, as stated in the Experimental section (Preparation of Chinese wolfberry fruit extract). A suspension that exhibits an absolute zeta potential more than $20 \mathrm{mV}$ is often considered stable, which can prevent the precipitation of NPs from solution. ${ }^{32}$ The zeta potential of $\mathrm{Au}-\mathrm{Ag}$ alloy NPs suspension obtained by the above extract is $-27.9 \mathrm{mV}$, displayed in Fig. S1. $\dagger$ Accordingly, the concentration of the wolfberry fruit extract provided in our experiment is suitable for the synthesis of stable $\mathrm{Au}-\mathrm{Ag}$ alloy NPs.

\section{SPR wavelength control of Au-Ag alloy NPs}

Generally, the SPR wavelength of Au-Ag alloy NPs, attributed to the interaction between free electrons on their surface and light, can be controlled by three key factors: the kind of the reductant, the $\mathrm{Au}^{3+} / \mathrm{Ag}^{+}$molar ratio in raw materials, and the synthesis time..$^{33-35}$ Up to now, based on green synthesis methods, it is difficult to flexibly change the SPR wavelength of $\mathrm{Au}-\mathrm{Ag}$ alloy NPs in one-pot when the $\mathrm{Au}^{3+} / \mathrm{Ag}^{+}$molar ratio in raw materials is fixed. ${ }^{17-20}$ To obtain eco-friendly Au-Ag alloy NPs, the wolfberry fruit extract was used as reductant and surfactant. Fig. 2 shows the effects of the $\mathrm{Au}^{3+} / \mathrm{Ag}^{+}$molar ratio and the synthesis time on the SPR wavelength of $\mathrm{Au}-\mathrm{Ag}$ alloy NPs. As exhibited in Fig. 2a, the SPR wavelength of $\mathrm{Au}-\mathrm{Ag}$ alloy NPs synthesized at $0.5 \mathrm{~min}$ locates at $495 \mathrm{~nm}$, which implies the reduction rate of $\mathrm{Au}^{3+}$ ions is faster than that of $\mathrm{Ag}^{+}$ions in the wolfberry fruit extract. It can be seen from Fig. 2a-c, the SPR wavelength of Au-Ag alloy NPs is blue-shifted with increasing synthesis time, which suggests the molar ratio of $\mathrm{Ag}$ element in $\mathrm{Au}-\mathrm{Ag}$ alloy NPs is continuously enhanced. ${ }^{10}$ In Fig. 2d, the relationship between the SPR wavelength and the synthesis time is demonstrated. In order to rapidly and linearly adjust the SPR wavelength in one-pot, the whole variation interval of the SPR wavelength from 490 to $430 \mathrm{~nm}$ could be divided into three subintervals to be individually controlled. The approximately linear relationships were established as follows:
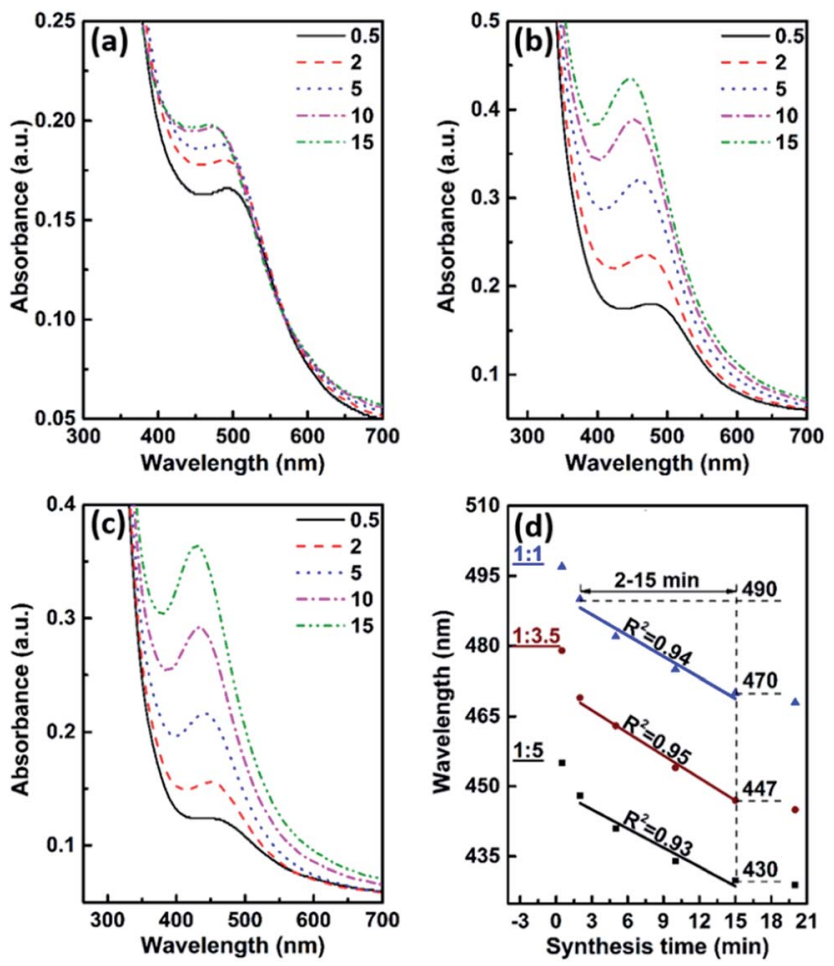

Fig. 2 UV-vis spectra of Au-Ag alloy NPs synthesized at different $\mathrm{Au}^{3+} / \mathrm{Ag}^{+}$molar ratio in raw materials. (a) $1: 1$, (b) $1: 3.5$, (c) $1: 5$. (d) The relationship between the SPR wavelength and the synthesis time. 


$$
\begin{gathered}
Y_{\mathrm{w}}=490-1.432 t\left(\mathrm{Au}^{3+}: \mathrm{Ag}^{+}=1: 1\right) \\
Y_{\mathrm{w}}=470-1.657 t\left(\mathrm{Au}^{3+}: \mathrm{Ag}^{+}=1: 3.5\right) \\
Y_{\mathrm{w}}=450-1.281 t\left(\mathrm{Au}^{3+}: \mathrm{Ag}^{+}=1: 5\right)
\end{gathered}
$$

Here, $Y_{\mathrm{w}}$ is the SPR wavelength, and $t$ is the synthesis time. The range of $t$ is from 2 to $15 \mathrm{~min}$. When the $\mathrm{Au}^{3+} / \mathrm{Ag}^{+}$molar ratio was kept as $1: 1$, the SPR wavelength could be linearly adjusted from 490 to $470 \mathrm{~nm}$ based on eqn (1). Decreasing the $\mathrm{Au}^{3+} / \mathrm{Ag}^{+}$ molar ratio to $1: 3.5$, the SPR wavelength could be continuously tuned between $470 \mathrm{~nm}$ and $450 \mathrm{~nm}$ according to eqn (2). In order to obtain Au-Ag alloy NPs with much shorter SPR wavelength ranged from 450 to $430 \mathrm{~nm}$, the $\mathrm{Au}^{3+} / \mathrm{Ag}^{+}$molar ratio needed to be decreased to $1: 5$. And then their SPR wavelength could be estimated from the eqn (3). Clearly, in each subinterval, the SPR wavelength could be flexibly controlled just through changing the synthesis time from 2 to $15 \mathrm{~min}$, which improved the conventional point-to-point synthesis technology. ${ }^{18-20}$

\section{Composition analysis of Au-Ag alloy NPs}

EDX analysis was applied to determine the presence of elements in $\mathrm{Au}-\mathrm{Ag}$ alloy NPs. Fig. 3 displays a typical EDX elemental mapping of $\mathrm{Au}-\mathrm{Ag}$ alloy NPs with the SPR wavelength of $430 \mathrm{~nm}$ synthesized at the $\mathrm{Au}^{3+} / \mathrm{Ag}^{+}$molar ratio of $1: 5$. In EDX spectrum, the obvious element peaks appeared at $\mathrm{Au}$ regions and $\mathrm{Ag}$ regions, which revealed synthesized NPs contained only Au and $\mathrm{Ag}$ elements without any other impurities such as $\mathrm{Cl}^{-}$ precipitation.

ICP analysis was used to accurately obtain the molar ratio of $\mathrm{Au}$ element and $\mathrm{Ag}$ element in $\mathrm{Au}-\mathrm{Ag}$ alloy NPs. The relationship between the SPR wavelength of $\mathrm{Au}-\mathrm{Ag}$ alloy NPs and their composition is shown in the inset of Fig. 3. $\mathrm{Au}-\mathrm{Ag}$ alloy NPs with the SPR wavelengths at $490 \mathrm{~nm}, 460 \mathrm{~nm}$, and $430 \mathrm{~nm}$ are

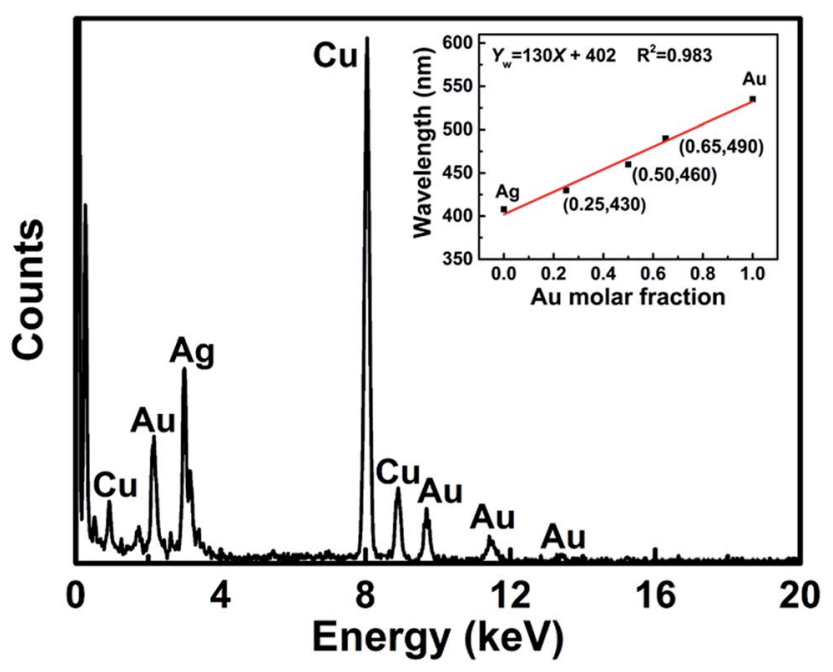

Fig. 3 EDX spectrum of Au-Ag alloy NPs with the SPR wavelength of $430 \mathrm{~nm}$ synthesized at the $\mathrm{Au}^{3+} / \mathrm{Ag}^{+}$molar ratio of $1: 5$ in raw materials. Inset is the plot of the SPR wavelength against the Au molar fraction in Au-Ag alloy NPs. individually corresponding to $\mathrm{Au}_{0.65} \mathrm{Ag}_{0.35}, \mathrm{Au}_{0.50} \mathrm{Ag}_{0.50}$, and $\mathrm{Au}_{0.25} \mathrm{Ag}_{0.75}$. It could be found that the SPR wavelength of $\mathrm{Au}-\mathrm{Ag}$ alloy NPs was blue-shifted with the increase of Ag content in $\mathrm{Au}-$ $\mathrm{Ag}$ alloy NPs. Generally, Au-Ag alloy NPs with a homogeneous composition can be confirmed through examining a single SPR peak and a linear relationship between the SPR wavelength of $\mathrm{Au}-\mathrm{Ag}$ alloy NPs and the $\mathrm{Au}$ molar fraction in $\mathrm{Au}-\mathrm{Ag}$ alloy NPs. ${ }^{9,36,37}$ In Fig. 2, only one peak is exhibited in each UV-vis spectrum, which just illustrates synthesized NPs have an alloy structure rather than a core-shell structure or a mixture of monometallic NPs. ${ }^{38}$ According to the inset of Fig. 3, the relationship between the SPR wavelength and the Au element molar fraction was fitted linearly as follows:

$$
Y_{\mathrm{w}}=130 X+402
$$

Here, $Y_{\mathrm{w}}$ is the SPR wavelength, and $X$ is the Au molar fraction in $\mathrm{Au}-\mathrm{Ag}$ alloy NPs. Eqn (4) further manifested as-obtained $\mathrm{Au}-\mathrm{Ag}$ alloy NPs had homogeneous composition without gradient. Based on the eqn (1)-(4), the composition of Au-Ag alloy NPs could also be linearly controlled by the synthesis time.

XPS was used to measure the surface composition of $\mathrm{Au}-\mathrm{Ag}$ alloy NPS with the SPR wavelength of $430 \mathrm{~nm}$. In Fig. 4a, the survey spectrum of Au-Ag alloy NPs reveals the presence of both $\mathrm{Au}$ and $\mathrm{Ag}$ elements and the absence of $\mathrm{AgCl}$ precipitation (197.5 eV), which is corresponding to the result of EDX analysis (Fig. 3). And there are another two obvious peaks at $399 \mathrm{eV}$ and $285 \mathrm{eV}$, which can be assigned to $\mathrm{N} 1 \mathrm{~s}$ and $\mathrm{C} 1 \mathrm{~s}$, respectively. It implied that a large amount of $\mathrm{N}$ and $\mathrm{C}$ elements were present on the surface of the Au-Ag alloy NPs. Combined with the FT-IR analysis, it was further confirmed that protein, amides and carbohydrate acted as surfactants. In Fig. $4 \mathrm{~b}$ and c, the peaks for $\mathrm{Au} 4 \mathrm{f}$ appear at 83.9 and $87.6 \mathrm{eV}$, and the peaks for $\mathrm{Ag} 3 \mathrm{~d}$ position at 368.0 and $374.0 \mathrm{eV}$. The gap between the $4 \mathrm{f}_{7 / 2}$ and $4 \mathrm{f}_{5 / 2}$ peaks of $\mathrm{Au}(D=3.7 \mathrm{eV})$ and that between the $3 \mathrm{~d}_{5 / 2}$ and $3 \mathrm{~d}_{3 /}$ 2 peaks of $\mathrm{Ag}(D=6.0 \mathrm{eV})$ were exactly the same as the values for zero-valent $\mathrm{Au}$ and $\mathrm{Ag}$, which demonstrated that $\mathrm{Au}$ and $\mathrm{Ag}$ atoms existed in a zero-valent state in the surface of Au-Ag alloy NPs. ${ }^{18}$ Compared with the binding energies of corresponding monometallic NPs, there were tiny energy shifts in $\mathrm{Au} 4 \mathrm{f}$ and $\mathrm{Ag}$ $3 \mathrm{~d}$ regions, which further suggested the formation of $\mathrm{Au}-\mathrm{Ag}$ alloy structure. ${ }^{18,39}$ Based on the XPS analysis, the molar ratio of $\mathrm{Au}$ element and $\mathrm{Ag}$ element in the surface of $\mathrm{Au}-\mathrm{Ag}$ alloy NPs was about $1: 3$, which was consistent with the result of ICP analysis (inset of Fig. 3). The surface composition was equal to the bulk composition, which was further indicated that the composition of obtained $\mathrm{Au}-\mathrm{Ag}$ alloy NPs was homogeneous.

\section{Morphology and microstructure analyses of Au-Ag alloy NPs}

Fig. 5a-c depict TEM images and size distributions of $\mathrm{Au}-\mathrm{Ag}$ alloy NPs synthesized at the $\mathrm{Au}^{3+} / \mathrm{Ag}^{+}$molar ratio of $1: 3.5$ at different synthesis times. It can be found that obtained NPs are sphere-like and have narrow size distribution. With the extension of the synthesis time from 0.2 to $60 \mathrm{~min}$, the average size of $\mathrm{Au}-\mathrm{Ag}$ alloy NPs increases gradually from 5.1 to $14.8 \mathrm{~nm}$. In Fig. 5d, the TEM image and the size distribution show that $\mathrm{Au}-$ $\mathrm{Ag}$ alloy NPs synthesized at the $\mathrm{Au}^{3+} / \mathrm{Ag}^{+}$molar ratio of $1: 5$ at 

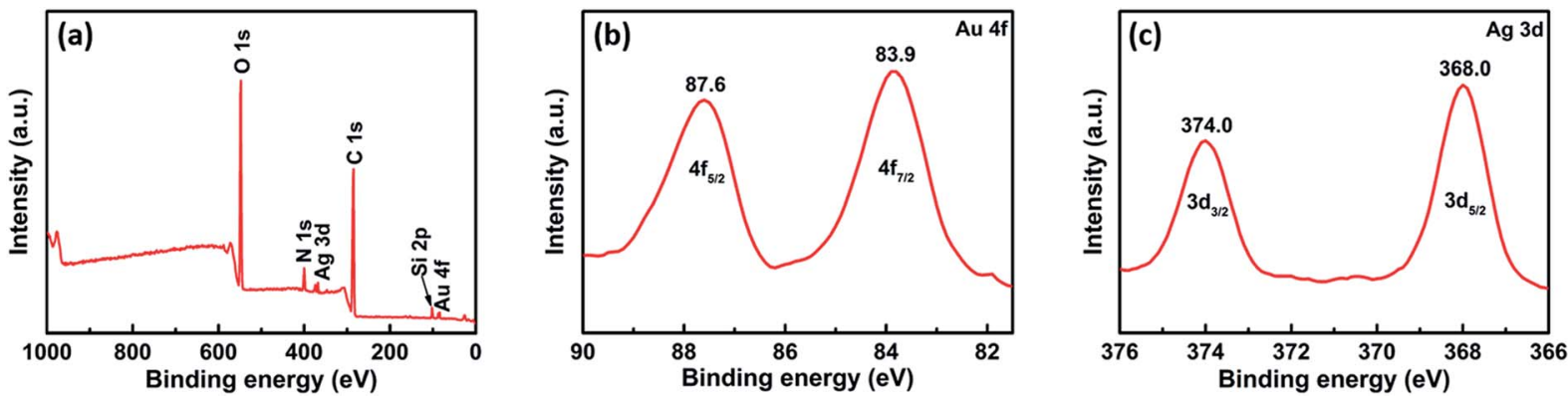

Fig. 4 XPS spectra of Au-Ag alloy NPs with the SPR wavelength of $430 \mathrm{~nm}$ synthesized at the $\mathrm{Au}^{3+} / \mathrm{Ag}^{+}$molar ratio of $1: 5$ in raw materials. (a) Survey, (b) high resolution Au 4f, and (c) high resolution Ag 3d.

$15 \mathrm{~min}$ have the average size of $10.9 \mathrm{~nm}$. Comparing $\mathrm{Au}-\mathrm{Ag}$ alloy NPs from Fig. $5 \mathrm{c}$ and d, although they have the same composition $\left(\mathrm{Au}_{0.25} \mathrm{Ag}_{0.75}\right), \mathrm{Au}-\mathrm{Ag}$ alloy NPs from Fig. $5 \mathrm{~d}$ have a smaller average size. Clearly, the $\mathrm{Au}^{3+} / \mathrm{Ag}^{+}$molar ratio in raw materials has a noticeable effect on not only the synthesis time (Fig. 2d) but also the average size of prepared $\mathrm{Au}-\mathrm{Ag}$ alloy NPs. In Fig. 5e, the interplanar distance measured from the adjacent lattice fringes is $0.24 \mathrm{~nm}$, corresponding to (111) planes of the facecentered cubic (fcc) $\mathrm{Au}$ or $\mathrm{Ag}$. It can also be found from Fig. 5e, $\mathrm{Au}_{0.25} \mathrm{Ag}_{0.75}$ alloy NPs tend to adopt an icosahedral morphology with a multiple-twinned structure..$^{18}$ In fcc metallic NPs with a small size, the multi-twinned icosahedral structure is frequently observed. ${ }^{40}$ The crystalline nature of $\mathrm{Au}_{0.25} \mathrm{Ag}_{0.75}$ alloy NPs is further confirmed via the SAED analysis in Fig. $5 f$. The electron diffraction pattern exhibits five diffraction rings corresponding to (111), (200), (220), (311), and (222) reflections of fcc $\mathrm{Au}$ or $\mathrm{Ag}$, suggesting the polycrystalline nature of $\mathrm{Au}_{0.25} \mathrm{Ag}_{0.75}$ alloy NPs.

\section{Proposed synthesis mechanism of Au-Ag alloy NPs}

Based on the wolfberry fruit extract, a possible synthesis mechanism of $\mathrm{Au}-\mathrm{Ag}$ alloy NPs is shown schematically in Fig. 6. The whole synthesis process can be divided into three stages: hydrolysis, nucleation and growth. When the wolfberry fruit
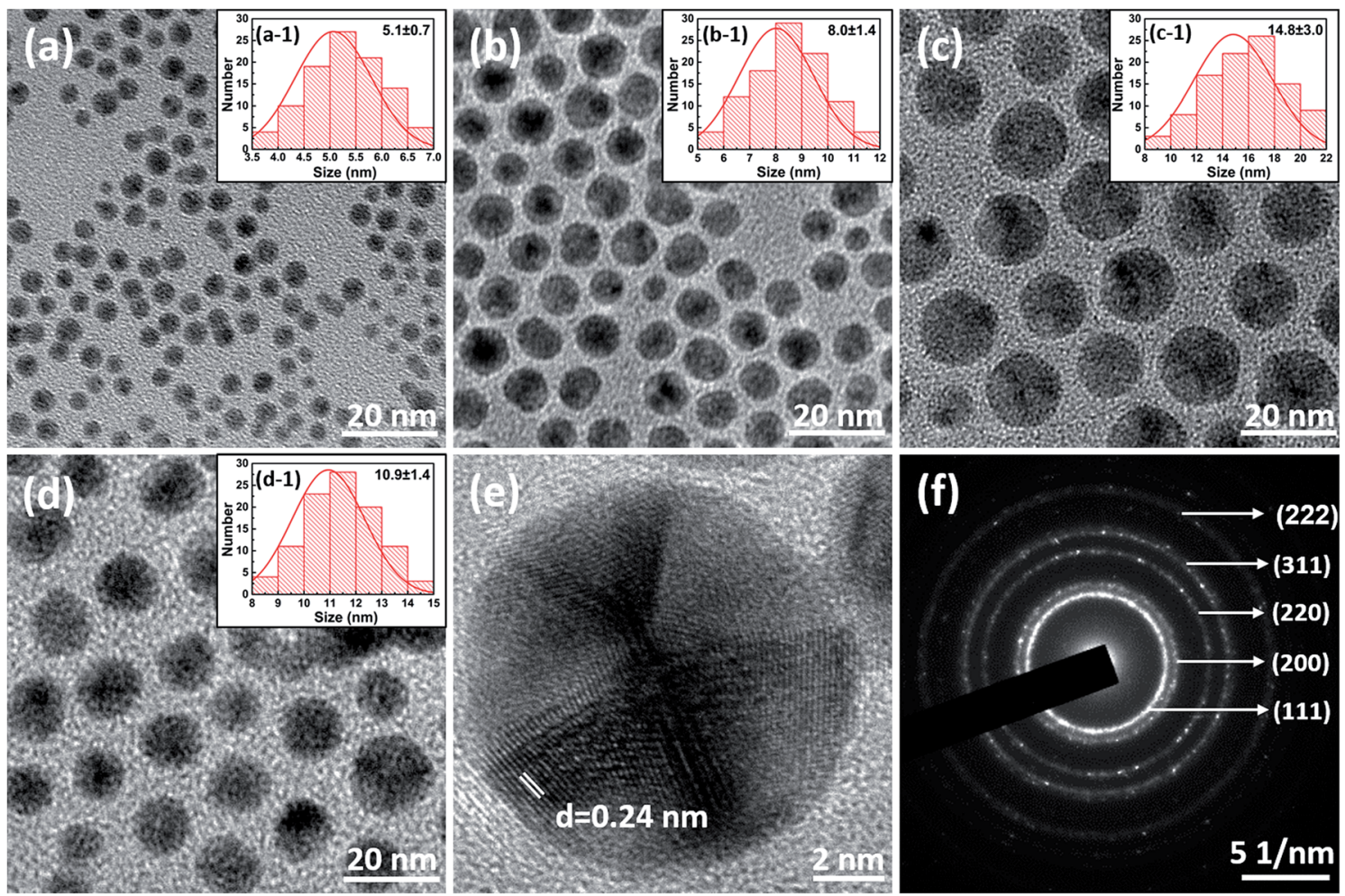

Fig. 5 TEM images and size distributions of $\mathrm{Au}-\mathrm{Ag}$ alloy NPs synthesized at the $\mathrm{Au}^{3+} / \mathrm{Ag}^{+}$molar ratio of $1: 3.5$ at different synthesis times. (a) and (a-1) $\mathrm{Au}_{0.65} \mathrm{Ag}_{0.35}$ t: $0.2 \mathrm{~min}$, (b) and (b-1) $\mathrm{Au}_{0.50} \mathrm{Ag}_{0.50}$ t: $5 \mathrm{~min}$, (c) and (c-1) $\mathrm{Au}_{0.25} \mathrm{Ag}_{0.75}$ t: 60 min. (d) TEM image and size distribution of $\mathrm{Au}_{0.25} \mathrm{Ag}_{0.75}$ alloy NPs synthesized at the $\mathrm{Au}^{3+} / \mathrm{Ag}^{+}$molar ratio of $1: 5$ at $15 \mathrm{~min}$. (e) HR-TEM image of $\mathrm{Au}_{0.25} \mathrm{Ag}_{0.75}$ alloy NPs. (f) The selected area electron diffraction pattern of $\mathrm{Au}_{0.25} \mathrm{Ag}_{0.75}$ alloy NPs. 


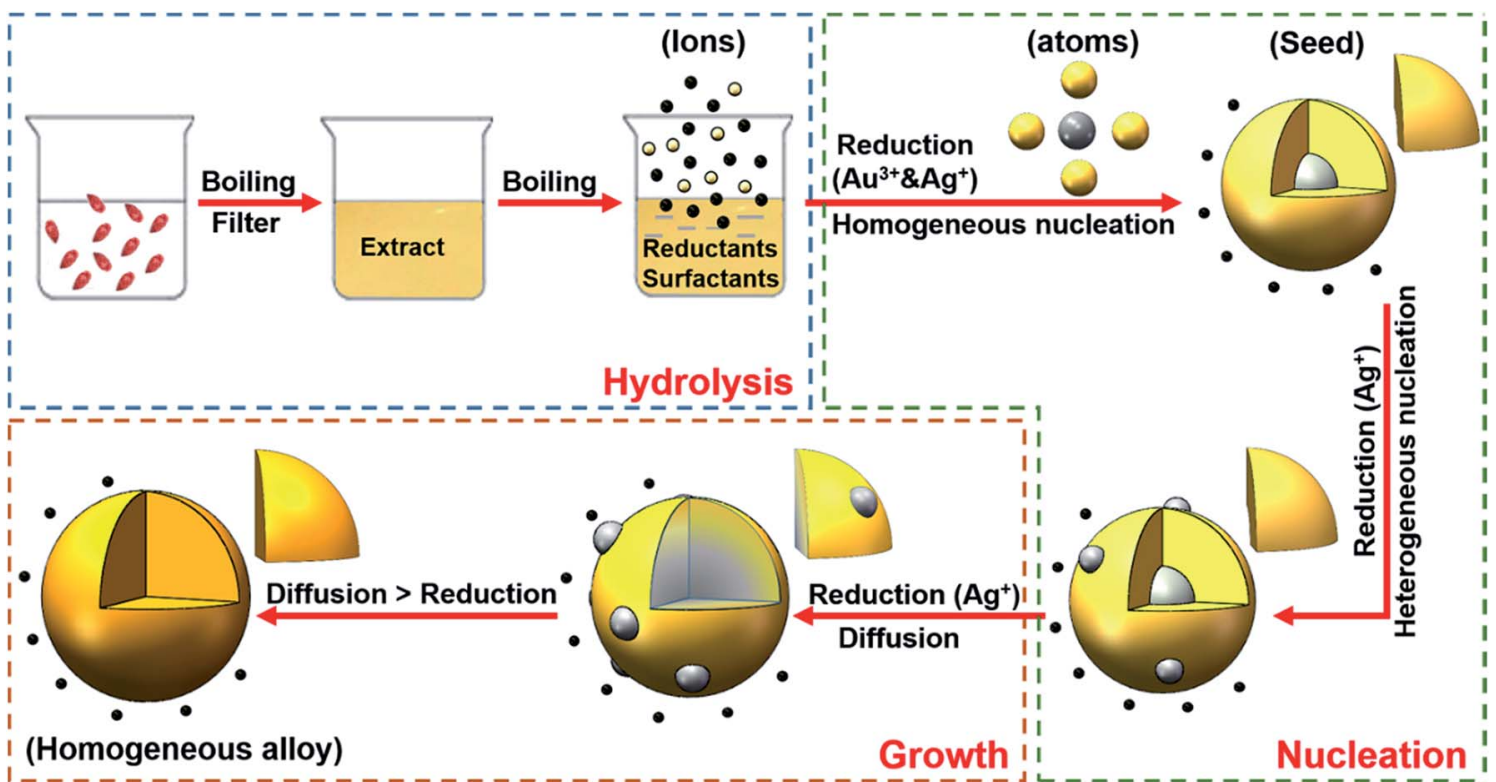

- Wolfberry fruit

- Au ion

- Ag ion

Au atom

$\mathrm{Ag}$ atom

Fig. 6 Schematic illustration of possible mechanism of synthesizing Au-Ag alloy NPs.

extract is heated to boiling, the hydrolysis begins. During the hydrolysis stage, polysaccharide is changed into monosaccharide and protein is transformed to amino acids and peptides, which can result in an enhancement of the reducibility of the wolfberry fruit extract. As a result, the synthesis time is shortened compared with the room-temperature synthesis using the wolfberry fruit extract as reductant. ${ }^{28}$ And these biomolecules cover on the surface of NPs and serve as surfactants, which can prevent the aggregation of NPs. The nucleation stage can be divided into the two parts: homogeneous nucleation and heterogeneous nucleation. In the period of homogeneous nucleation, when the mixture of $\mathrm{HAuCl}_{4}$ and $\mathrm{AgNO}_{3}$ aqueous solution is rapidly injected into the boiling wolfberry fruit extract, both $\mathrm{Au}$ ions and $\mathrm{Ag}$ ions are reduced simultaneously, accompanying with the generation of $\mathrm{Au}-\mathrm{Ag}$ bimetallic nuclei as the seeds to further form $\mathrm{Au}-\mathrm{Ag}$ alloy NPs. During the above stage, $\mathrm{Au}$ ions are depleted, but $\mathrm{Ag}$ ions just have a low consumption because of their relative slow reduction rate (see Table S1 in the ESI $\dagger$ ). Thus, Au element can be rich in the surface of the initial $\mathrm{Au}-\mathrm{Ag}$ bimetallic seed. In the stage of the heterogeneous nucleation, $\mathrm{Ag}$ ions are reduced continuously and then obtained $\mathrm{Ag}$ atoms are deposited on the surface of the $\mathrm{Au}-\mathrm{Ag}$ bimetallic seed. In the growth stage, the composition of $\mathrm{Au}-\mathrm{Ag}$ alloy NPs is dependent on the reduction rate of $\mathrm{Ag}$ ions and the synthesis time, which can be reflected from the UV-vis spectra (Fig. 2). The microstructure of $\mathrm{Au}-\mathrm{Ag}$ alloy NPs is mainly depended on the relative rate between the reduction rate of $\mathrm{Ag}$ ions and the mutual diffusion rate of $\mathrm{Au}$ element and $\mathrm{Ag}$ element. Only is the diffusion rate higher than the reduction rate, $\mathrm{Au}-\mathrm{Ag}$ alloy NPs with homogeneous alloy structure can be obtained..$^{41}$ Otherwise, synthesized $\mathrm{Au}-\mathrm{Ag}$ alloy NPs can have a gradient or disordered alloy structure. ${ }^{38}$ The reduction rate of $\mathrm{Ag}$ ions is connected with the temperature and their content in raw materials. Therefore, the minimum value of the $\mathrm{Au}^{3+} / \mathrm{Ag}^{+}$ molar ratio in raw materials is set at $1: 5$ in our experiment. According to the Boltzmann-Arrhenius equation, the diffusion rate is also associated with the temperature. ${ }^{42}$ In our experiment, the boiling point is considered as a suitable temperature for the synthesis of homogeneous Au-Ag alloy NPs. Based on the analysis of the synthesis mechanism, it is beneficial for the controllable synthesis of other bimetallic alloy NPs.

\section{Photocatalytic activity of $\mathrm{Au}-\mathrm{Ag}$ alloy NPs}

In order to research the photocatalytic properties of $\mathrm{Au}-\mathrm{Ag}$ alloy NPs with varying composition, the reduction reactions of 2,3 , 4-NP using $\mathrm{NaBH}_{4}$ as reductant were systematically investigated. Firstly, the reduction of 4-NP was taken as an example. Upon the addition of $\mathrm{NaBH}_{4}$ into 4-NP solution, the UV-vis absorption peak of $400 \mathrm{~nm}$ was appeared immediately, indicating the formation of 4-nitrophenolate anions. In the absence of the photocatalyst, the peak at $400 \mathrm{~nm}$ remained undiminished even for several hours. However, when the $\mathrm{Au}-\mathrm{Ag}$ alloy NPs hydrosol was added into the reaction system, the absorbance of the peak at $400 \mathrm{~nm}$ declined quickly and a new peak emerged immediately at $300 \mathrm{~nm}$ indicating the formation of 4-AP (Fig. 7a-c). It suggested $\mathrm{Au}-\mathrm{Ag}$ alloy NPs with varying composition all had the photocatalytic activity for the reduction of 4-NP. In Fig. S2 and S3,† Au-Ag alloy NPs also show obvious photocatalytic activities for the reduction reactions of 3-NP and 2-NP. Here, Au-Ag alloy NPs played two important roles in the reduction reactions of 2, 3, 4-NP. Firstly, these NPs provided plentiful surface active sites, which accelerated the reaction between $\mathrm{BH}_{4}{ }^{-}$and water following the generation of a large amount of hydrogen gas (eqn S1 in the ESI $\dagger$ ). Abundant hydrogen gas promoted the reduction rates of 2, 3, 4-NP in their 

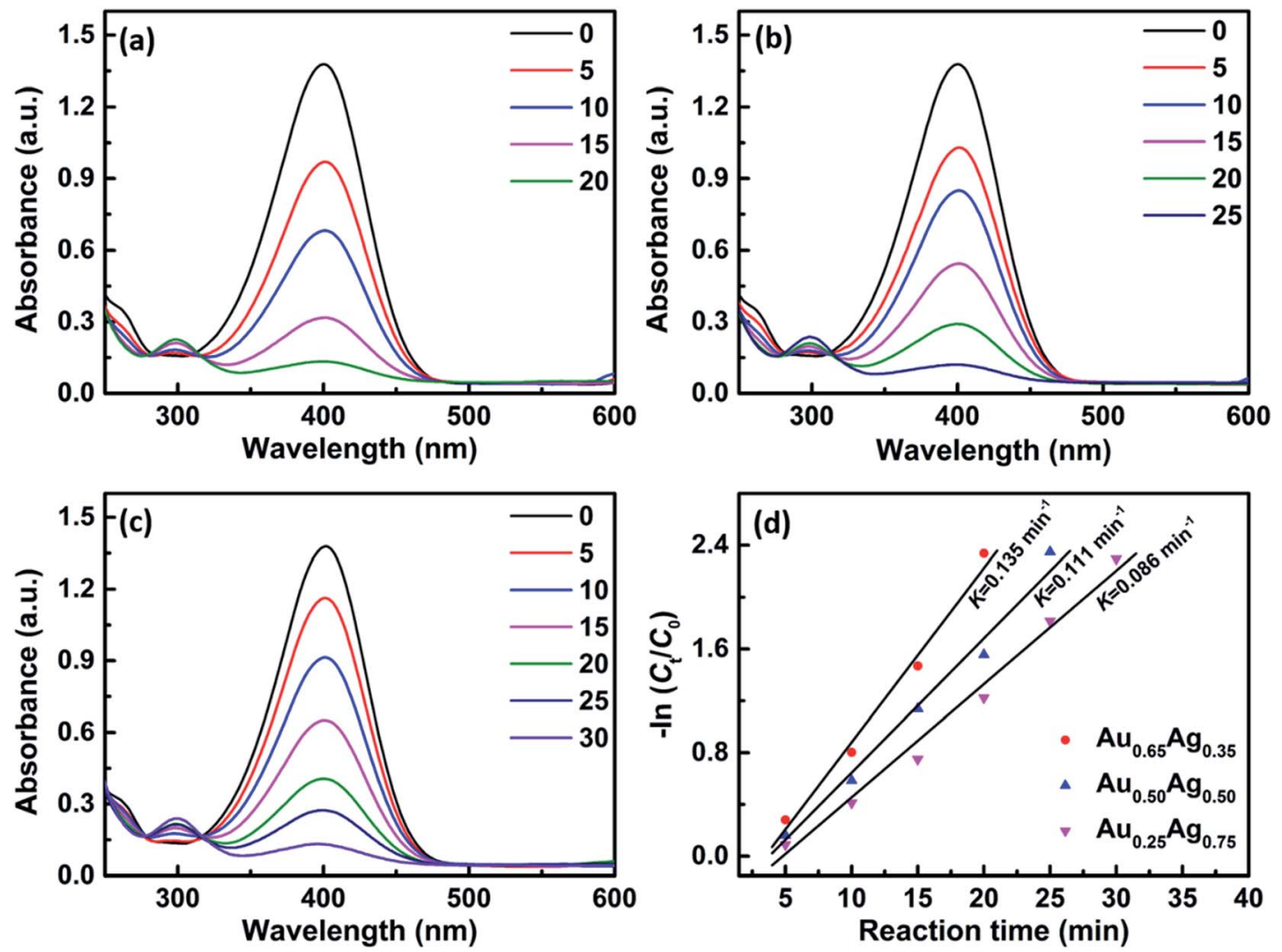

Fig. 7 UV-vis absorption spectra of the reduction of 4-NP solution mixed with $500 \mu \mathrm{L}$ of different Au-Ag alloy NPs hydrosol, (a) Au 0.65 Ago.35, (b) $\mathrm{Au}_{0.50} \mathrm{Ag}_{0.50}$, and (c) $\mathrm{Au}_{0.25} \mathrm{Ag}_{0.75}$. (d) The plots of $-\ln \left(C_{t} / C_{0}\right)$ versus the reaction time based on different NPs.

hydrogenation reactions (eqn S2 in the ESI $\dagger$ ). ${ }^{43}$ On the other hand, $\mathrm{Au}-\mathrm{Ag}$ alloy NPs ensured the selective reduction of the nitro group $\left(-\mathrm{NO}_{2}\right)$ and avoided the formation of by-products. ${ }^{44}$

The rate constant is often considered as an important parameter to evaluate the activity of photocatalyst. ${ }^{25,45}$ When the amount of $\mathrm{NaBH}_{4}$ is in excess, the kinetics of photocatalytic reactions can be described according to the pseudo-first-order equation as given below:

$$
\ln \left(C_{t} / C_{0}\right)=-K t
$$

Here, $K$ is the rate constant, $t$ is the reaction time, and $C_{t}$ and $C_{0}$ are the concentration of the nitro compound at time $t$ and its initial concentration, respectively. ${ }^{46}$ Fig. $7 \mathrm{~d}, \mathrm{~S} 2 \mathrm{~d}$ and $\mathrm{S} 3 \mathrm{~d} \dagger$ display the rate constants, which are corresponding to the slopes of the fitted linear relationships between $-\ln \left(C_{t} / C_{0}\right)$ and the reaction time. It could be found that the photocatalytic activity of Au-Ag alloy NPs was enhanced with the increase of the Au molar fraction in Au-Ag alloy NPs. The photocatalytic activity of NPs was often dependent on their size, composition and microstructure. ${ }^{19,25,45}$ According to Malathi's opinion, the composition of $\mathrm{Au}-\mathrm{Ag}$ alloy NPs had a much stronger effect on the photocatalytic activity compared with their size. ${ }^{45}$ Nevertheless, up to now, the relation of their composition and activity has not been established. As shown in Table S2, $\uparrow$ there is no significant change among the average sizes of Au-Ag alloy NPs with different composition. Therefore, it could be further inferred that the enhancement of the photocatalytic activity of $\mathrm{Au}-\mathrm{Ag}$ alloy NPs was ascribed to the increase of the Au molar fraction in Au-Ag alloy NPs. In Fig. 8, the accurate relationship between the composition of $\mathrm{Au}-\mathrm{Ag}$ alloy NPs and the rate constant of photocatalytic reaction is depicted. For example, a linear relation between $\mathrm{Au}$ molar fraction and the rate constant of the reduction of 4-NP is shown as follows:

$$
K=0.125 X+0.050
$$

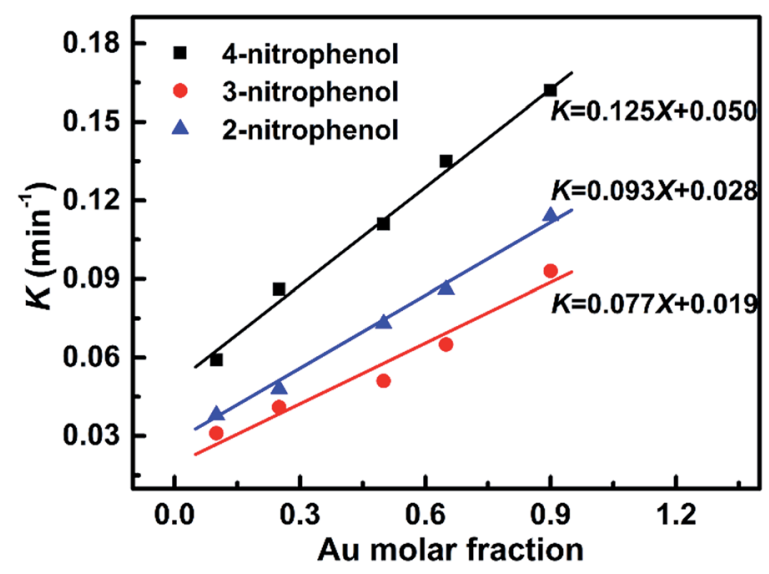

Fig. 8 Effects of the Au molar fraction in Au-Ag alloy NPs on the rate constant based on different photocatalytic reactions. 
Here, $K$ is the rate constant, and $X$ is the Au element molar fraction in Au-Ag alloy NPs. The eqn (6) suggests the rate constant can be linearly controlled through adjusting the composition of Au-Ag alloy NPs. Combining eqn (1)-(4) and (6), the relationship equation between the rate constant and the synthesis parameters (the $\mathrm{Au}^{3+} / \mathrm{Ag}^{+}$molar ratio in raw materials and the synthesis time) can be established as follows:

$$
\begin{gathered}
K=0.135-1.377 \times 10^{-3} t\left(\mathrm{Au}^{3+}: \mathrm{Ag}^{+}=1: 1\right) \\
K=0.115-1.593 \times 10^{-3} t\left(\mathrm{Au}^{3+}: \mathrm{Ag}^{+}=1: 3.5\right) \\
K=0.096-1.232 \times 10^{-3} t\left(\mathrm{Au}^{3+}: \mathrm{Ag}^{+}=1: 5\right)
\end{gathered}
$$

Here, $t$ is the synthesis time to prepare $\mathrm{Au}-\mathrm{Ag}$ alloy NPs, whose range is from 2 to $15 \mathrm{~min}$. Thus, the variation range of the rate constant is from 0.132 to $0.078 \mathrm{~min}^{-1}$. Based on above equations, the rate constant can be predetermined just through setting the synthesis parameters during the preparation of $\mathrm{Au}-$ $\mathrm{Ag}$ alloy NPs. Similarly, the corresponding equations between the rate constant and the synthesis parameters can also be established for the reduction reactions of 2-NP and 3-NP. The variation ranges of their rate constants are from 0.089 to $0.049 \mathrm{~min}^{-1}$ and from 0.069 to $0.036 \mathrm{~min}^{-1}$, respectively. It can also be noteworthy in Fig. 8, basing the same photocatalyst, the rate constant of the reduction of 4-NP is highest, which can be attributed to the electron withdrawing effect and steric effect. ${ }^{45}$ The above method to control the rate constant provides a promising route for other photocatalytic reactions using bimetallic alloy NPs as photocatalyst.

Besides the above method, the rate constant can also be adjusted by the addition amount of Au-Ag alloy NPs hydrosol. Based on different addition amount of $\mathrm{Au}_{0.65} \mathrm{Ag}_{0.35}$ alloy NPs hydrosol, the rate constant of the reduction of 4-NP is displayed in Fig. 9. The rate constant was enhanced with increasing addition amount. As shown in the inset of Fig. 9, the

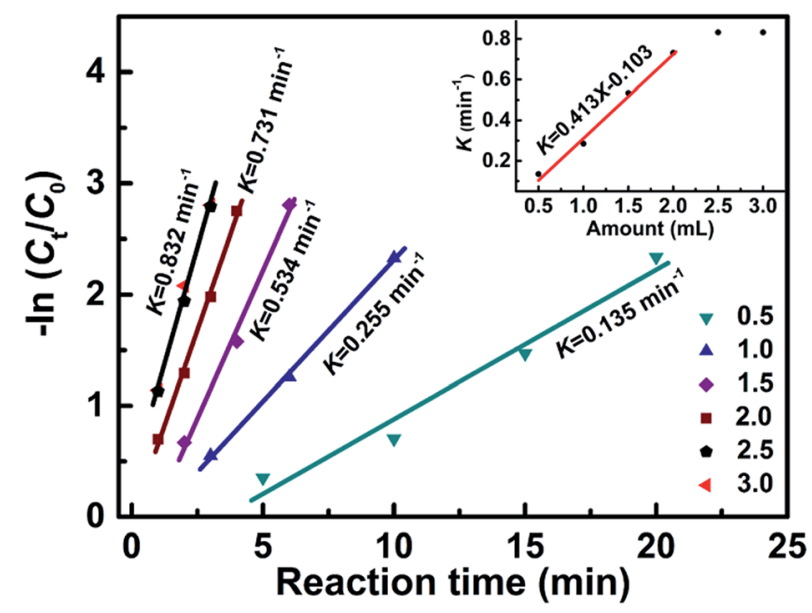

Fig. 9 The plots of $-\ln \left(C_{t} / C_{0}\right)$ versus the reaction time for the reduction of 4-NP based on different addition amount of $\mathrm{Au}_{0.65} \mathrm{Ag}_{0.35}$ alloy NPs hydrosol. Inset is the relationship of the rate constant and the amount of Au-Ag alloy NPs hydrosol. relationship between the rate constant and the addition amount of $\mathrm{Au}_{0.65} \mathrm{Ag}_{0.35}$ alloy NPs hydrosol is linearly fitted as follows:

$$
K=0.413 X-0.103
$$

Here, $K$ is the rate constant. $X$ is the addition amount, whose range is from 0.5 to $2.0 \mathrm{~mL}$. When the addition amount was more than $2.0 \mathrm{~mL}$, the rate constant had no remarkable change and could not be linearly controlled. Therefore, the linear controllable range of the rate constant was from 0.135 to $0.731 \mathrm{~min}^{-1}$. In Fig. 9, it can also be found the maximum value of the rate constant for the reduction of 4 -NP is $0.832 \mathrm{~min}^{-1}$, which is comparable with those reported results, for example $0.798 \mathrm{~min}^{-1}$ for $\mathrm{Au}-\mathrm{Ag}$ alloy NPs synthesized by the fruit juice of Pomegranate, $0.106 \mathrm{~min}^{-1}$ for $\mathrm{Au}-\mathrm{Ag}$ alloy NPs prepared by isonicotinic acid hydrazide and starch, and $1.134 \mathrm{~min}^{-1}$ for hollow $\mathrm{Au}-\mathrm{Ag}$ bimetallic NPs obtained by maltose and Pluronic F127. ${ }^{20,45,47}$ As far as the methodology is concerned, the synthesis of $\mathrm{Au}-\mathrm{Ag}$ alloy NPs based on the Chinese wolfberry fruit extract is much more facile, efficient and controllable. ${ }^{18-20,45,47}$ Therefore, the technical route provided in this work may have enormous potential in the field of photocatalysis.

It is well-known that $\mathrm{Ag}$ is easy to be oxidized. The stability of $\mathrm{Au}-\mathrm{Ag}$ alloy NPs must be investigated for practical engineering applications. Guo et al. reported the photocatalytic performance of hollow porous Au NPs (80 nm) had no significant change after 30 days. ${ }^{25}$ As revealed in Fig. $10, \mathrm{Au}_{0.25} \mathrm{Ag}_{0.75}$ alloy NPs also exhibit an excellent stability after 3 months, which indicates the stability of Au-Ag alloy NPs with a high Ag content and a small size of $10.9 \mathrm{~nm}$ is comparable with that of Au NPs with a large size of $80 \mathrm{~nm}$. XRD patterns of fresh $\mathrm{Au}_{0.25} \mathrm{Ag}_{0.75}$ alloy NPs and $\mathrm{Au}_{0.25} \mathrm{Ag}_{0.75}$ alloy NPs used as photocatalyst after three months are exhibited in Fig. 11. XRD peaks were well consistent with the data of the JCPDS \#04-0784 file of Au with the cubic phase (or the JCPDS \#04-0783 file of Ag). The diffraction peaks at $2 \theta$ value of $38.2^{\circ}, 44.4^{\circ}, 64.6^{\circ}, 77.6^{\circ}$ could be assigned to (111), (200), (220), and (311) lattice planes of fcc Au or Ag. Clearly, Ag

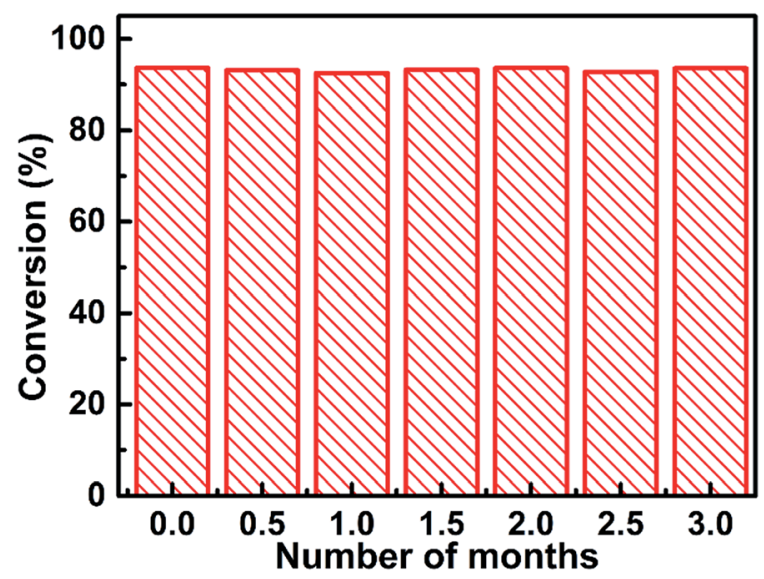

Fig. 10 The conversion efficiency of 4-NP to 4-AP using $500 \mu \mathrm{L}$ of $\mathrm{Au}_{0.25} \mathrm{Ag}_{0.75}$ alloy NPs hydrosol in three months. 


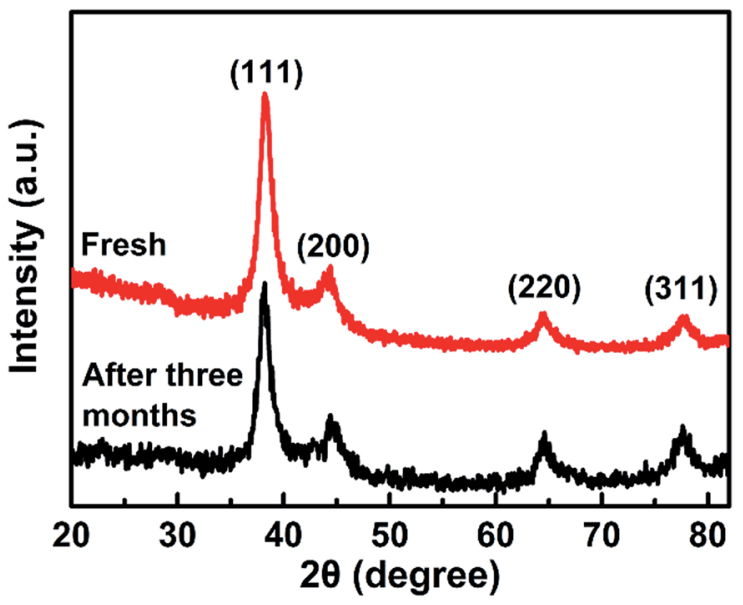

Fig. 11 XRD patterns of fresh $\mathrm{Au}_{0.25} \mathrm{Ag}_{0.75}$ alloy NPs (a) and $\mathrm{Au}_{0.25} \mathrm{Ag}_{0.75}$ alloy NPs used as photocatalyst after three months (b).

element overcame the weakness of chemical instability by combining Au element, which was an obvious advantage of $\mathrm{Au}-$ $\mathrm{Ag}$ alloy NPs compared with monometallic Ag NPs.

\section{Conclusions}

$\mathrm{Au}-\mathrm{Ag}$ alloy NPs were synthesized using the Chinese wolfberry fruit extract as reductant and surfactant without any toxic or polluting agent. The whole synthesis process less than $25 \mathrm{~min}$ could be divided into three stages: hydrolysis, nucleation and growth. The green synthesis method, fast, flexible and simple, can be extended to the continuous synthesis of other bimetallic alloy NPs in one-pot. Obtained $\mathrm{Au}-\mathrm{Ag}$ alloy NPs exhibited obvious photocatalytic activities in reduction reactions of 2-, 3-, 4-NP. And the rate constants of the photocatalytic reactions followed the order: $k_{4-\mathrm{NP}}>k_{2-\mathrm{NP}}>k_{3-\mathrm{NP}}$. Compared with the size, the composition of $\mathrm{Au}-\mathrm{Ag}$ alloy NPs had a more significant effect on their photocatalytic activity. The addition amount of $\mathrm{Au}-\mathrm{Ag}$ alloy NPs hydrosol displayed a linear relation with the rate constant. Moreover, the rate constant could also be linearly adjusted by $\mathrm{Au}$ molar fraction in $\mathrm{Au}-\mathrm{Ag}$ alloy NPs or by the synthesis parameters of $\mathrm{Au}-\mathrm{Ag}$ alloy NPs. The above methods to control the rate constant provided promising routes for other photocatalytic reactions using $\mathrm{Au}-\mathrm{Ag}$ alloy NPs as photocatalysts.

\section{Conflicts of interest}

There are no conflicts to declare.

\section{Acknowledgements}

The authors appreciate the financial support of the National Natural Science Foundation of China (No. 11404210).

\section{References}

1 Y. Iizuka, R. Inoue, T. Miura, N. Morita, T. Honma and H. Oji, Appl. Catal., A, 2014, 483, 63-75.
2 Q. Y. Han, C. Y. Zhang, W. Gao, Z. H. Han, T. Z. Liu, C. X. Li, Z. J. Wang, E. J. He and H. R. Zheng, Sens. Actuators, B, 2016, 231, 609-614.

3 A. Q. Wang, C. M. Chang and C. Y. Mou, J. Phys. Chem. B, 2005, 109, 18860-18867.

4 W. Y. Li and F. Y. Chen, J. Alloys Compd., 2015, 632, 845848.

5 F.-H. Ko, M.-R. Tai, F.-K. Liu and Y.-C. Chang, Sens. Actuators, $B, 2015,211,283-289$.

6 L. Chang, Z. P. Liu and D. J. Cheng, J. Alloys Compd., 2015, 653, 363-368.

7 N. Kumar, F. Alam and V. Dutta, J. Alloys Compd., 2014, 585, 312-317.

8 M. J. Hostetler, C.-J. Zhong, B. K. H. Yen, J. Anderegg, S. M. Gross, N. D. Evans, M. Porter and R. W. Murray, J. Am. Chem. Soc., 1998, 120, 9396-9397.

9 S. Link, Z. L. Wang and M. A. EI-Sayed, J. Phys. Chem. B, 1999, 103, 3529-3533.

10 C. Wang, H. F. Yin, R. Chan, S. Peng, S. Dai and S. H. Sun, Chem. Mater., 2009, 21, 433-435.

11 Q. B. Zhang, J. Y. Lee, J. Yang, C. Boothroyd and J. X. Zhang, Nanotechnology, 2007, 18, 245605-245612.

12 P. Quaresma, L. Soares, L. Contar, A. Miranda, I. Osório, P. A. Carvalho, R. Franco and E. Pereira, Green Chem., 2009, 11, 1889-1893.

13 S. Pugazhendhi, E. Kirubha, P. K. Palanisamy and R. Gopalakrishnan, Appl. Surf. Sci., 2015, 357, 1801-1808.

14 Y. Konishi, K. Ohno, N. Saitoh, T. Nomura, S. Nagamine, H. Hishida, Y. Takahashi and T. Uruga, J. Biotechnol., 2007, 128, 648-653.

15 R. Gopalakrishnan, B. Loganathanb and K. Raghu, RSC Adv., 2015, 5, 31691-31699.

16 M. M. Wang, W. J. Zhang, X. S. Zheng and P. Z. Zhu, RSC Adv., 2017, 7, 12144-12149.

17 S. U. Ganaie, T. Abbasi and S. A. Abbasi, J. Exp. Nanosci., 2016, 11, 395-417.

18 G. L. Zhang, M. M. Du, Q. B. Li, X. L. Li, J. L. Huang, X. D. Jiang and D. H. Sun, RSC Adv., 2013, 3, 1878-1884.

19 R. Gopalakrishnan, B. Loganathan and K. Raghu, RSC Adv., 2015, 5, 31691-31699.

20 M. M. Kumari, J. Jacob and D. Philip, Spectrochim. Acta, Part A, 2015, 137, 185-192.

21 Z.-H. Lin, Z.-Y. Shih, P. Roy and H.-T. Chang, Chem.-Eur. J., 2012, 18, 12330-12336.

22 C. Fu, M. J. Li, H. J. Li, C. P. Li, X. G. Wu and B. H. Yang, J. Alloys Compd., 2017, 692, 727-733.

23 H. B. Zhang, G. G. Liu, L. Shi, H. M. Liu, T. Wang and J. H. Ye, Nano Energy, 2016, 22, 149-168.

24 S. L. Liu, A. Qileng, J. Y. Huang, Q. Z. Gao and Y. J. Liu, RSC Adv., 2017, 7, 45545-45551.

25 M. Z. Guo, J. He, Y. Li, S. Ma and X. H. Sun, J. Hazard. Mater., 2016, 310, 89-97.

26 X. Q. Liu, Y. G. Su, J. Y. Lang, Z. L. Chai and X. J. Wang, J. Alloys Compd., 2017, 695, 60-69.

27 W. B. Zhang, X. M. Xiao, T. C. An, Z. G. Song, J. M. Fu, G. Y. Sheng and M. C. Cui, J. Chem. Technol. Biotechnol., 2003, 78, 788-794. 
28 C. F. Dong, C. L. Cao, X. L Zhang, Y. L Zhan, X. J. Wang, X. Z. Yang, K. Z. Zhou, X. H. Xiao and B. Yuan, Optik, 2017, 130, 162-170.

29 X. Yao, S. Q. Sun, L. J. Xu, W. Xiao and Y. Peng, Her. Med., 2010, 29, 1065-1068.

30 L. Castro, M. L. Blazquez, F. Gonzalez, J. A. Munoz and A. Ballester, Chem. Eng. J., 2010, 164, 92-97.

31 V. Ahluwalia, J. Kumar, R. Sisodia, N. A. Shakil and S. Walia, Ind. Crops Prod., 2014, 55, 202-206.

32 A. M. El Badawy, T. P. Luxton, R. G. Silva, K. G. Scheckel, M. T. Suidan and T. M. Tolaymat, Environ. Sci. Technol., 2010, 44, 1260-1266.

33 S. Mondal, N. Roy, R. A. Laskar, I. Sk, S. Basu, D. Mandal and N. A. Begum, Colloids Surf., B, 2011, 82, 497-504.

34 A. Monga and B. Pal, Colloids Surf., A, 2015, 481, 158-166.

35 L. Sun, W. L. Luan and Y.-J. Shan, Nanoscale Res. Lett., 2012, 7, 1-6.

36 P. Raveendran, J. Fu and S. L. Wallen, Green Chem., 2006, 8, 34-38.

37 S. Devarajan, P. Bera and S. Sampath, J. Colloid Interface Sci., 2005, 290, 117-129.
38 D. V. Radziuk, W. Zhang, D. Shchukin and H. Mohwald, Small, 2010, 6, 545-553.

39 N. N. Kariuki, J. Luo, M. M. Maye, S. A. Hassan, T. Menard, H. R. Naslund, Y. H. Lin, C. M. Wang, M. H. Engelhard and C. J. Zhong, Langmuir, 2004, 20, 11240-11246.

40 Y. Xiong, J. M. McLellan, Y. Yin and Y. Xia, Angew. Chem., Int. Ed., 2007, 46, 790-794.

41 L. Sun, W. L. Luan, S.-T. Tu and Y. J. Shan, Chem. Eng. J., 2012, 189, 451-455.

42 C. Wang, S. Peng, R. Chan and S. H. Sun, Small, 2009, 5, 567570.

43 A. Mondal, A. Mondal, B. Adhikary and D. K. Mukherjee, Bull. Mater. Sci., 2017, 40, 321-328.

44 A. Corma, P. Concepción and P. Serna, Angew. Chem., Int. Ed., 2007, 46, 7266-7269.

45 S. Malathi, T. Ezhilarasu, T. Abiraman and S. Balasubramanian, Carbohydr. Polym., 2014, 111, 734-743. 46 J. Seralathan, P. Stexenson, S. Subramaniam, R. Raghavan, B. Pemaiah, A. Sivasubramanian and A. Veerappan, Spectrochim. Acta, Part A, 2014, 118, 349-355.

47 M. S. Holden, K. E. Nick, M. Hall, J. R. Milligan, Q. Chen and C. C. Perry, RSC Adv., 2014, 4, 52279-52288. 